\title{
Effect of Bee Bread on Pregnancy Outcomes and Reproductive System of Rats under Heat Stress Exposure
}

\author{
Nur Akmar Nadhirah Mohd Nor, Connie Fay Komilus, Mohd Nizam Haron, \\ Fathurrahman Lananan, Ha Hou Chew, Nadzifah Yaakub, Asmad Kari* \\ Malaysia School of Animal Science, Aquatic Science and Environment, Faculty of \\ Bioresources and Food Industry, Universiti Sultan Zainal Abidin, 22200 Besut, \\ Terengganu, Malaysia
}

Abstract Exposure to extreme temperature during pregnancy was associated with abnormal birth outcomes including preterm birth, low birth weight, and placental abortion. Bee bread is a natural product created by bees that is highly nutritional and was recommended for human consumption as a source of high energy and protein. Hence, this study aims to determine the effect of bee bread on pregnancy outcomes and the reproductive organs (i.e. ovary and uterus) of the Sprague Dawley rats exposed to heat stress. Pregnant Sprague Dawley rats were divided into four treatment groups (Control (C: standard feeding); Treatment 1 (T1: Bee bread); Treatment 2 (T2: Heat stress) and Treatment 3 (T3: Bee bread + Heat stress)). Rats from T1 and T3 groups received bee bread $(0.5 \mathrm{~g} / \mathrm{kg}$ body weight/day) orally using oral gavage starting from day-0 of pregnancy until delivery, while rats from $\mathrm{T} 2$ and $\mathrm{T} 3$ groups were exposed to $43^{\circ} \mathrm{C}$ of heat by using an egg incubator for $45 \mathrm{~min} /$ day until delivery. After delivery, pregnancy outcomes were assessed and the dams were euthanised. Reproductive organs were dissected and weighed. Rats in the T2 group had significantly $(p<0.05)$ decreased litter size and foetal birth weight as well as an increased percentage of resorption and increased gestation period when compared with $\mathrm{C}$ and $\mathrm{T} 1$ groups. T3 group had shown improvement as positive effects of bee bread during heat stress exposure on litter size, foetal birth weight and percentage of resorption. It can be concluded that bee bread supplementation has beneficial effects on the adverse effects of pregnancy in rats subject to heat stress.

Keywords: Heat stress, bee bread, female reproduction, pregnancy outcomes

*For correspondence: asmad@unisza.edu.my

Received: 4 July 2021

Accepted: 24 Nov 2021

(C) Copyright Nor et al. This article is distributed under the terms of the Creative

Commons Attribution License, which permits unrestricted use and redistribution provided that the original author and source are credited.

\section{Introduction}

Most mammals maintained a body temperature above environment temperature through the generation of metabolic heat. However, when the body temperature rises above normal, the effect of heat stress starts to appear. When both temperature and humidity increase, the higher the risk of heat stress occurs [1]. Heat stress is a natural hazard that has a detrimental effect on human health, resulting in an increased incidence of mortality (death), morbidity (illness) $[2,3,4,5,6]$, high risk of respiratory disease [7], and cardiovascular disease [8,9,10].

Heat stress has been shown to harm reproductive performance, including oogenesis, oocyte maturation, fertilisation development, and implantation rate [11]. Studies on mice [12] and cows [13] show that exposing pregnant females to heat stress after fertilisation caused a reduction in the embryo's quality and quantity by decreasing the pregnancy rate and causing embryonic death [13,14]. This might be due to the inhibition of luteal function by heat stress that causes a reduction in progesterone levels, which function in follicular development as well as the initiation and maintenance of pregnancy [15]. 
Furthermore, maternal heat stress promotes prostaglandin F2 $\alpha$ (PGF2 $\alpha$ ) [16] that have been negatively associated with embryo quality and pregnancy rates [17]. In addition, exposure to extreme ambient temperature $\left(40^{\circ} \mathrm{C}\right)$ during pregnancy has an adverse impact on birth outcomes, including stillbirth, preterm birth, spontaneous abortion, growth retardation, developmental defects, and low birth weight $[18,19,20,21,22,23,24]$. The molecular mechanisms of heat stress causing these results are yet to be clarified.

However, it is reported that exposure to extreme temperatures (i.e. $\geq 31.2^{\circ} \mathrm{C}$ to $34.1^{\circ} \mathrm{C}$ ) during pregnancy was likely to induce high maternal stress [25]. In most studies, exposure to stressors activated the hypothalamic-pituitary-adrenal (HPA) axis and sympathetic nervous system (SNS) which lead to the release of corticotropin-releasing hormone $(\mathrm{CRH})$, adrenocorticotropin-releasing hormone $(\mathrm{ACTH})$, cortisol, and noradrenaline into the bloodstream [26]. Increasing maternal stress was also identified as a risk factor for the abnormal development of the foetus that resulted in preterm birth and low birth weight $[27,28]$.

Heat stress is likely to induce oxidative stress in animals [29]. It is reported that the concentration of oxidative stress marker, malondialdehyde (MDA) increases while the concentration of fat-soluble vitamins was decreased due to heat stress [20]. Heat stress raises energy metabolism and oxygen demand of tissues in the body, causing the increase of mitochondrial activity up to a thermal limit and also increasing the rate of reactive oxygen species (ROS) production [31]. The imbalance between the production of free radicals and the enzymatic defence mechanisms reduction triggered oxidative stress [32] that had affected several birth outcomes like miscarriage and premature rupture of the membranes $[33,34]$.

Honeybees products are known for their medicinal and health-promoting properties. Their broad biological effects have been known and are capable of counteracting the effects of oxidative stress. Bee bread is one of the products from bees that consist of pollen, honey and secretions of the bee's salivary gland $[35,36]$. Compared to pollen, bee bread contains a higher nutritional value, better digestibility, and richer chemical composition [37], including proteins, lipids, microelements, and vitamins [38]. It is also known to be abundant in antioxidants, both enzymatic and non-enzymatic, such as glucose oxidase, catalase, ascorbic acid, flavonoids, and phenolic compound $[39,40,41,42]$. Studies demonstrated that bee bread has an effect on the development of the digestive tract and improves the immune system and facilitates medicinal therapy. Bee bread proved to have some beneficial effects such as antimicrobial, anti-atherosclerotic activity, anti-ageing and anti-anaemic activity including effective antioxidant that has acted against active oxidative stress [43]. Hens fed with a $0.5 \mathrm{~g}$ bee bread/kg diet were found to produce significantly increased egg number and laying rate compared to the control group [44]. Furthermore, supplementation of $1 \mathrm{~g} / \mathrm{kg}$ body weight of bee bread has significantly reduced the percentage of abnormal sperm in adult rats [45]. In addition, bee bread also contains a local analgesic that can relieve pain due to stress or injury [46].

To date, a minimal study was done to determine the beneficial effect of bee bread supplementation in preventing or relieving the adverse effect of heat stress on pregnancy outcomes and reproductive performance. This study aimed to determine the effect of bee bread on pregnancy outcomes such as gestation length, litter size, birth weight, congenital abnormality, and percentage of resorption and the weight of the reproductive organs, including the ovary and uterus in rats exposed to heat stress.

\section{Materials and Methods}

\section{Experimental animals}

Twenty-four ( $n=24)$ of eight-week-old sexually matured female Sprague Dawley rats were used as the animal model in this study. All animals were housed individually in a cage supplied with clean and absorbent bedding and commercial pellet food and water ad libitum and maintained for a 12-hour light/dark cycle at a temperature of $20-24^{\circ} \mathrm{C}$. This study protocol was approved by the UniSZA Animal and Plant Research Ethics Committee (UAPREC/04/043). All dams were exposed to $43^{\circ} \mathrm{C}$ of heat for 45 $\mathrm{min} /$ day until delivery except for T2 and T3 groups.

\section{Determination of oestrous phases and mating}

Vagina smears of the virgin rats were obtained daily for ten consecutive days to determine the oestrous cycle regularity. The rats were restrained by proper handling methods to minimise stress and to prevent injury to the handler. The vagina fluid was collected by flushing the vagina with $0.9 \%$ normal saline using a blunt-ended pipette. The tip of the pipette is softly placed into the vaginal entrance to a depth of 2-5 
$\mathrm{mm}$, and the fluid is flushed into the vagina and back into the pipette two or three times by gently squeezing and releasing the pipette's bulb. If the fluid seems to be "cloudy" after the initial flush, no further flushing is required [47].

After that, a little portion of the cell suspension is ejected onto a glass slide that has been labelled before being examined under a light microscope with 100x and 400x magnifications. The proestrus or oestrus phase of the cycle was determined once the regularity of the cycle is obtained. The proestrus is characterised by epithelial cells that are rounded and usually nucleated, and occur in low to moderate (sometimes high) numbers. While oestrus phase consists mainly of cornified and non-nucleated cells in large numbers that form clumps and sheets [47].

Then, each female rat was mated with a proven fertile male (male that has reached matured sexual age and has successfully mated before) rats overnight to induce pregnancy. Each smear from the females was rechecked the following morning to determine the existence of sperm and a positive sperm smear was marked as day- 0 of pregnancy [48].

\section{Treatment groups}

Pregnant rats were randomised into four groups ( $n=6$ per group) which were Control (C: standard feeding), Treatment 1 (T1: $0.5 \mathrm{~g}$ bee bread/kg body weight/day), Treatment 2 (T2: standard feeding with heat exposure) and Treatment 3 (T3: $0.5 \mathrm{~g}$ bee bread/kg body weight/day with heat exposure). Bee bread $(0.5 \mathrm{~g} / \mathrm{kg}$ body weight/day) was given by force-feeding using oral gavage to the corresponding pregnant rats starting from day 0 of pregnancy until delivery [48].

The bee bread samples used in this study was the same as one of the bee bread samples that were subjected to a nutritional analysis done by Othman [49]. The bee bread was purchased from a local bee farm located in Kelantan. The bee bread was diluted with $1.0 \mathrm{ml}$ distilled water for easier administration of the bee bread by oral gavage. The doses of bee bread were based on human consumption which was one tablespoon daily or approximately $30 \mathrm{~g} / 60 \mathrm{~kg}$ of body weight [43]. Rats in C and T2 groups were given $1.0 \mathrm{ml}$ of distilled water daily to experience the same force-feeding procedure as T1 and T3 groups to avoid other stress interference. Heat stress was experimentally induced by placing both rats from T2 and T3 groups in an egg incubator (M\&M Ternak) for 45 minutes at a temperature of $43^{\circ} \mathrm{C}$ daily until delivered. This temperature and duration were modified from a previous study by Mohd Nor and Haron [50].

\section{Assessment of reproductive and pregnancy outcomes}

Once delivered, each dam was sacrificed by cervical dislocation. Reproductive organs (uterus and ovaries) were collected and weighed. Implantation sites of the uterus were counted to determine the percentage of resorption

The pregnancy outcomes such as day of delivery, litter size, birth weight, gross congenital abnormalities and percentage of resorption were assessed. The ratio of the difference between the litter size and the implantation sites were calculated to determine resorption. All pups were euthanised after being evaluated.

\section{Statistical analysis}

Statistical analysis was done using Minitab software. All the data collected with normal distribution were analysed using one way ANOVA followed by Tukey's post hoc test and the results were expressed as mean \pm SEM. Statistical significance was accepted at $p<0.05$.

\section{Results and Discussion}

\section{Reproductive organs weight}

The findings on ovary and uterus weights of 24 female Sprague Dawley rats are presented in Figure 1 and Figure 2. 


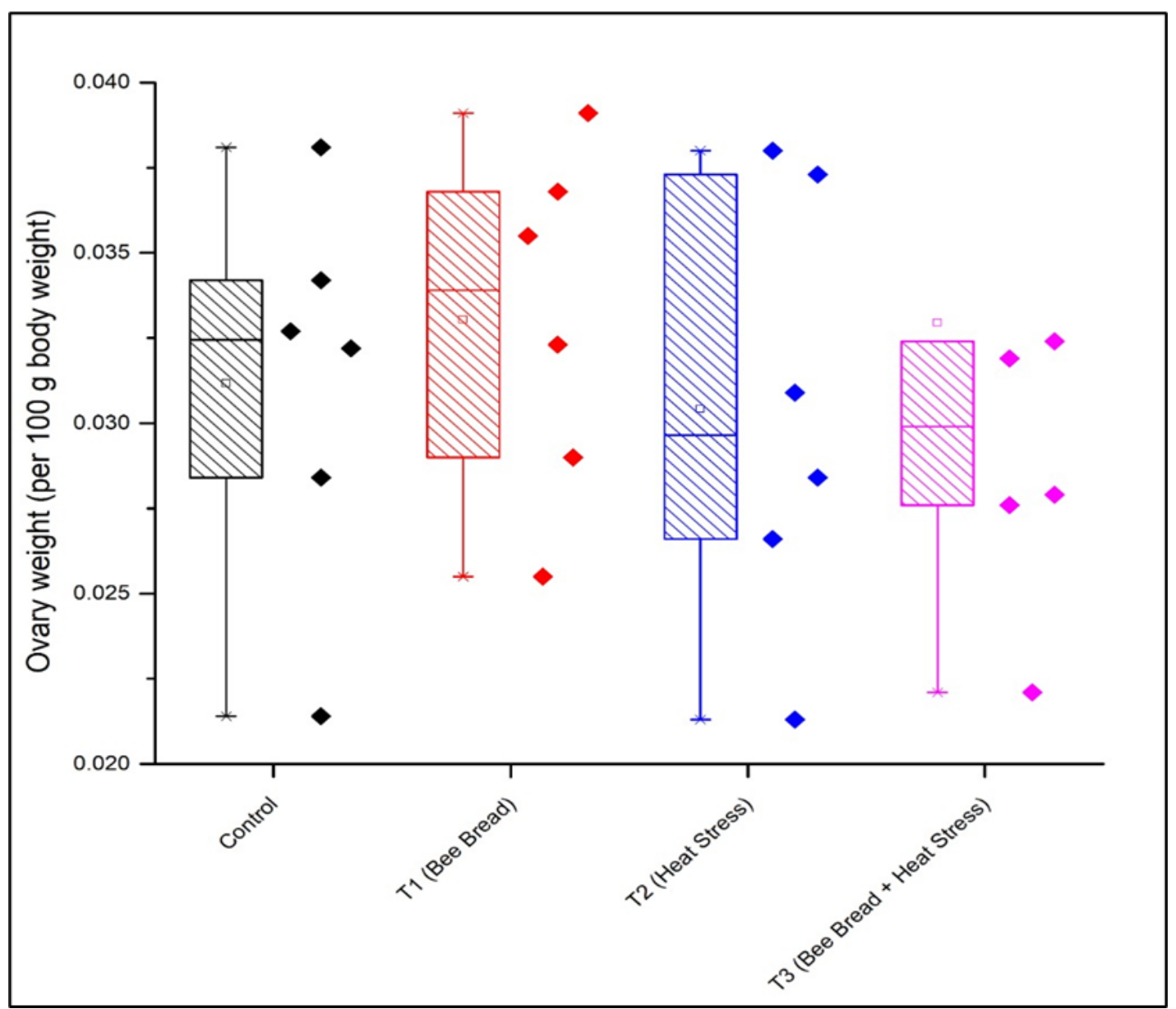

Figure 1. The ovary weight (mean \pm SEM) of female Sprague Dawley rats in different treatment groups which are Control (C: standard feeding treatment), Treatment 1 (T1: Bee bread), Treatment 2 (T2: Heat stress) and Treatment 3 (T3: Bee bread + Heat stress). The diamond shape with different colours indicates the data distribution of each group. 


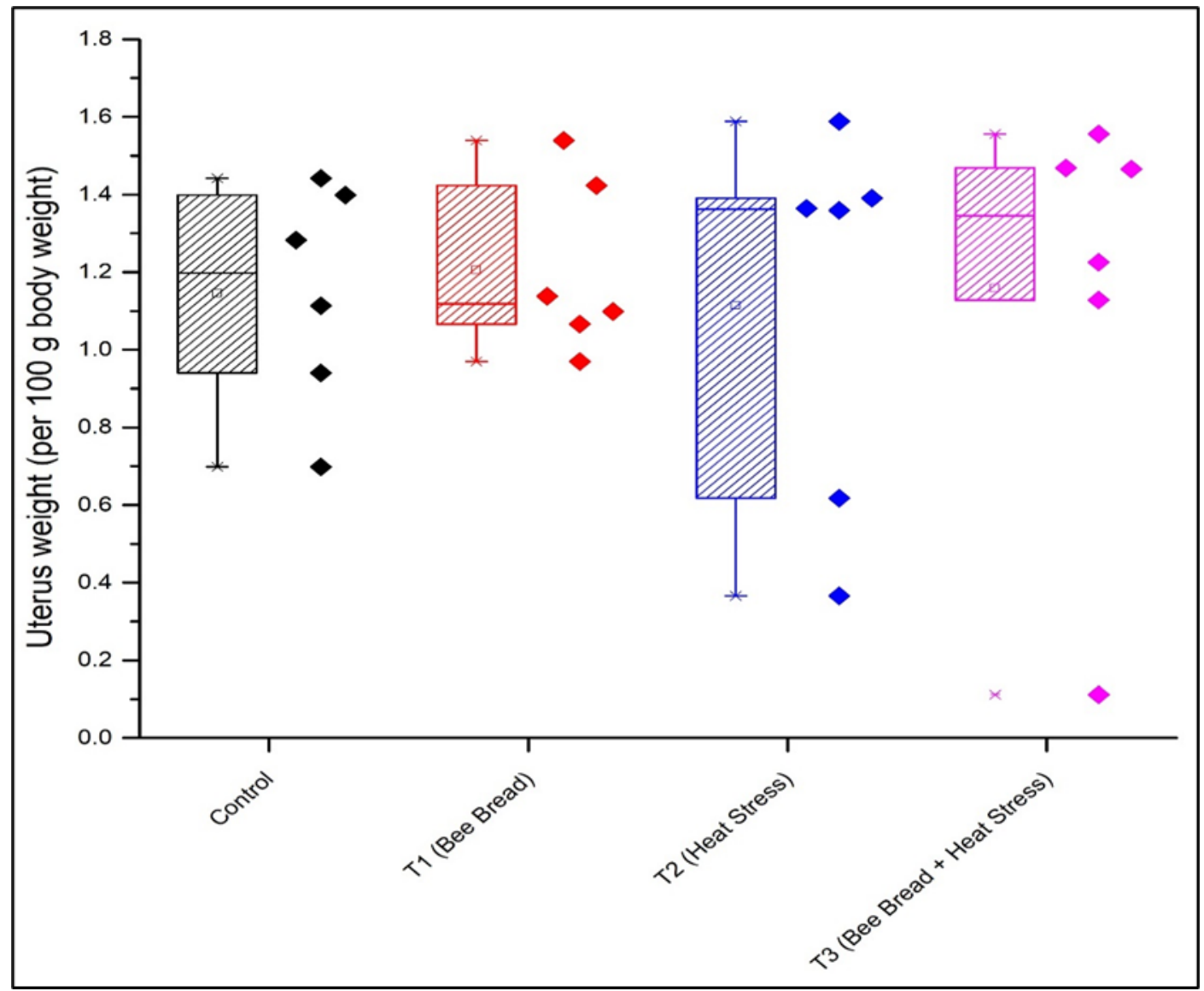

Figure 2. The uterus weight (mean \pm SEM) of female Sprague Dawley rats in different treatment groups which are Control (C: standard feeding treatment), Treatment 1 (T1: Bee bread), Treatment 2 (T2: Heat stress) and Treatment 3 (T3: Bee bread + Heat stress). The diamond shape with different colours indicates the data distribution of each group.

There were no differences observed in different treatment groups on ovary and uterus weights of the female Sprague Dawley rats. Fotsing [51] reported that exposure to chronic restraint stress had shown a decline in ovarian weight and uterus weight. Another study using different types of stress, such as chronic cold restraint and immobilisation stress also resulted in a significant decrease in the ovary and uterus weight [52]. However, a study by Namwanje and Brown [53] has indicated that the reduction in uterus weight was caused by the unavailability of hormones required for the uterus development, which are oestrogen and progesterone. According to Shivalingappa [54], an absence of gonadotrophic or steroidal hormones or both resulted in decreased stroma, follicles and corpus luteum activities thus, reducing the weight of the ovary. In adult goats, 48 hours of heat stress exposure caused the recruitment of ovulatory follicles delayed by about 24 hours and LH receptor levels were reduced [55]. Meanwhile, in the heat-tolerant bovine breed Gir [56], controlled heat stress day/night for 28 days had a negative impact on ovarian follicular development, hormone levels and oocyte competence [57]. Based on these contrast findings, it is plausible that the effect of stress may vary depending on the stressor's type, timing and duration. Thus, the 45 minutes exposure to $43^{\circ} \mathrm{C}$ temperature daily to the pregnant rats from day-1 of pregnancy until delivery of the pups is not likely to alter the ovary and uterus weights.

\section{Pregnancy outcomes}

The findings for all experimental groups on pregnancy outcomes are presented in Figure 3, Figure 4, Figure 5 and Figure 6 . The length of gestation in the T2 group was significantly $(P<0.05)$ higher than in the control group but not significantly $(P>0.05)$ different from the T1 and T3 groups (Figure 3$)$. 


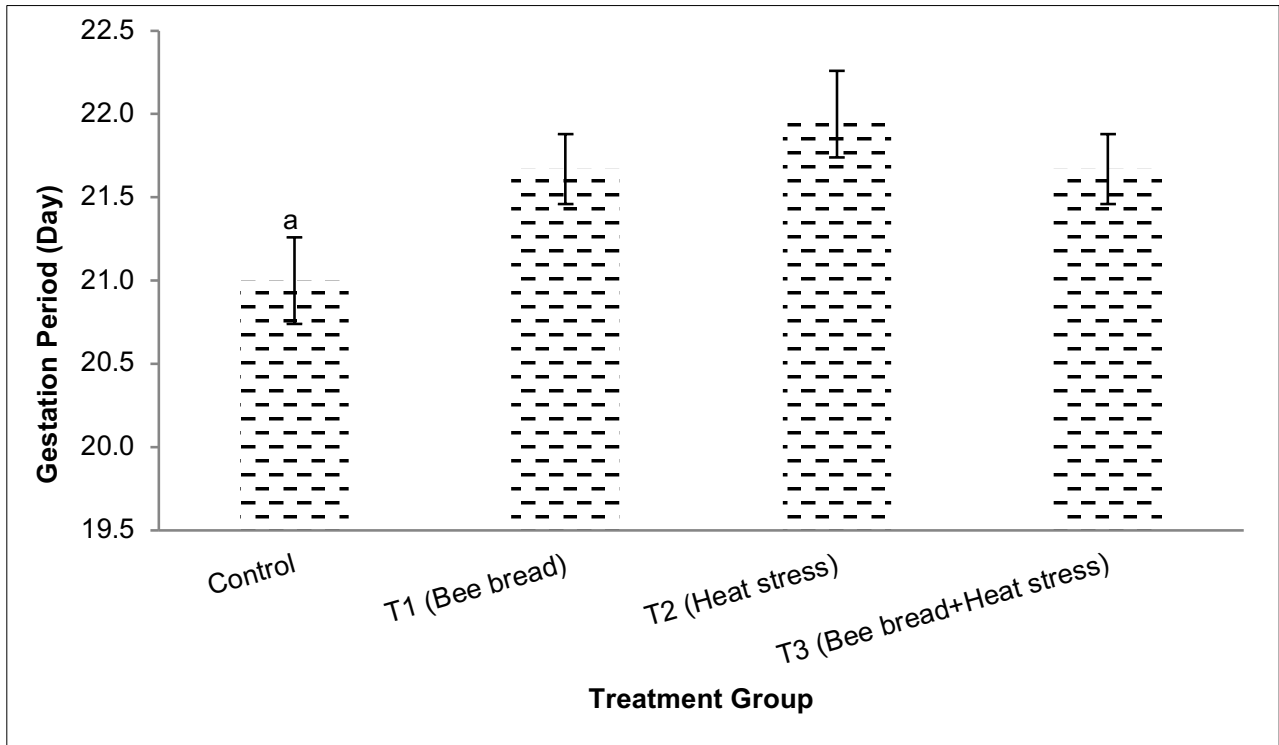

Significant differences were determined by one way ANOVA followed by Tukey's post hoc test with $p<0.05$ Different superscript $(a, b)$ indicates a significant difference.

Figure 3. The gestation period (mean \pm SEM) of female Sprague Dawley rats in different treatment groups which are Control (C: standard feeding treatment), Treatment 1 (T1: Bee bread), Treatment 2 (T2: Heat stress) and Treatment 3 (T3: Bee bread + Heat stress).

There was a significantly smaller litter size and a higher percentage of resorption in the T2 group compared with the control, T1 group and T3 groups (Figure 4). Although there are no significant differences observed in litter size among C, T1, and T3 groups; T3 which is under heat exposure had shown the recovery from stress after bee bread treatment by litter size similar to $\mathrm{C}$ and T1's litter size. Meanwhile, the T3 with bee bread treatment also decreased the percentage of resorption compared to T2 (Figure 5). This observation may indicate bee bread efficacy as a booster in improving pregnancy outcomes under heat stress by delivering similar litter size and decreasing the percentage of resorption as in normal control females.

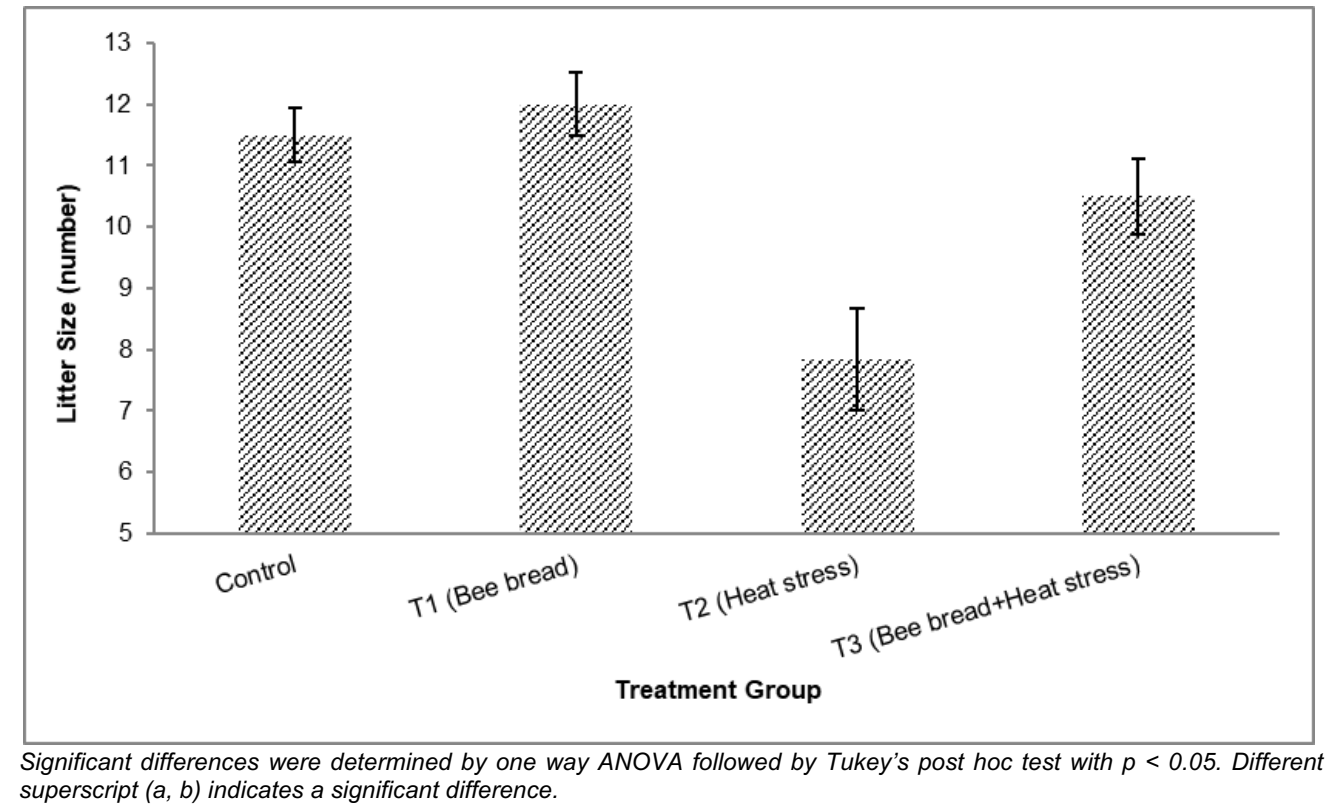

Figure 4. The litter size (mean \pm SEM) of female Sprague Dawley rats in different treatment groups which are Control (C: standard feeding treatment), Treatment 1 (T1: Bee bread), Treatment 2 (T2: Heat stress) and Treatment 3 (T3: Bee bread + Heat stress). 


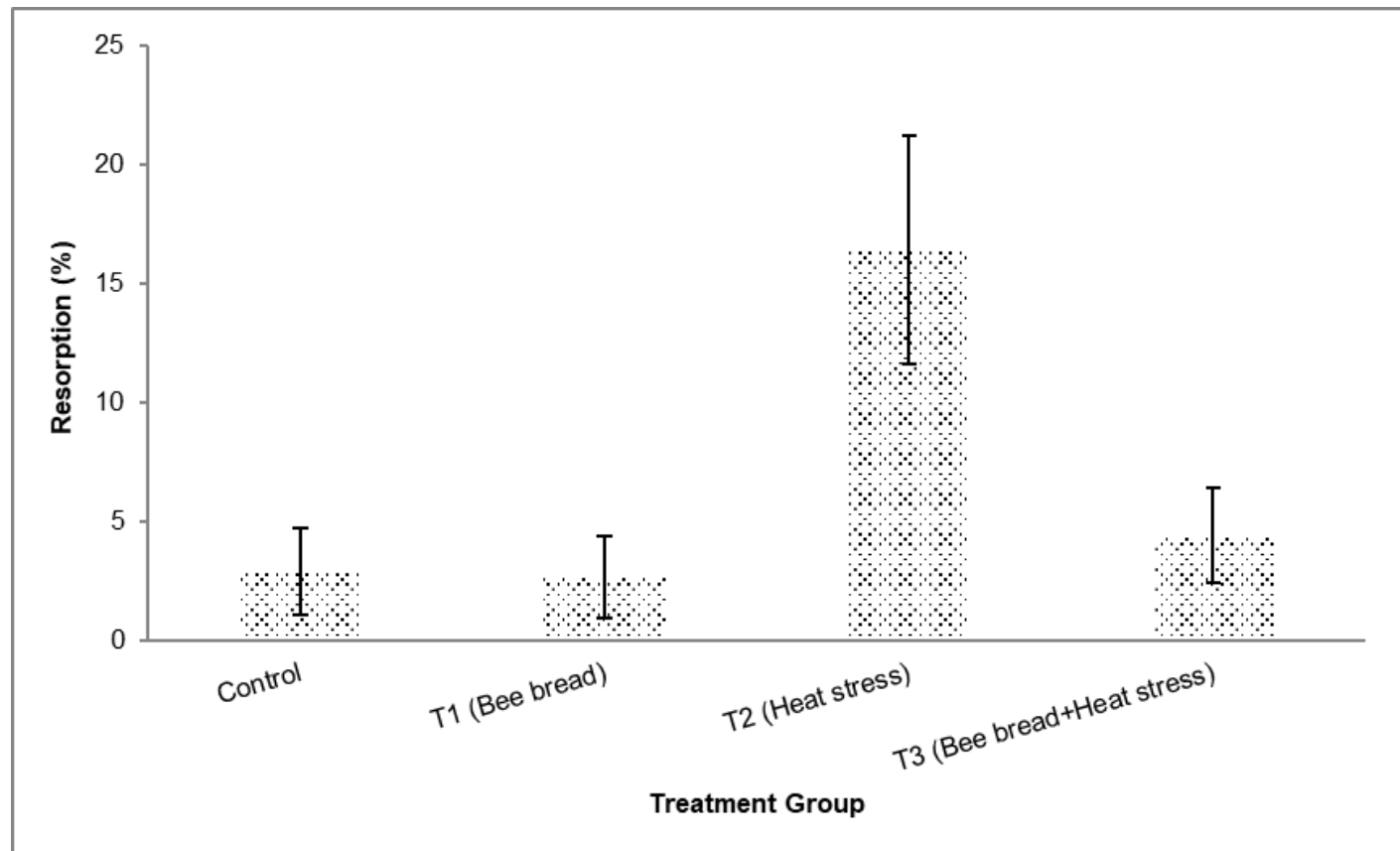

Significant differences were determined by one way ANOVA followed by Tukey's post hoc test with $p<0.05$. Different superscript $(a, b)$ indicates a significant difference.

Figure 5. The resorption (mean \pm SEM) of female Sprague Dawley rats in different treatment groups which are Control (C: standard feeding treatment), Treatment 1 (T1: Bee bread), Treatment 2 (T2: Heat stress) and Treatment 3 (T3: Bee bread + Heat stress).

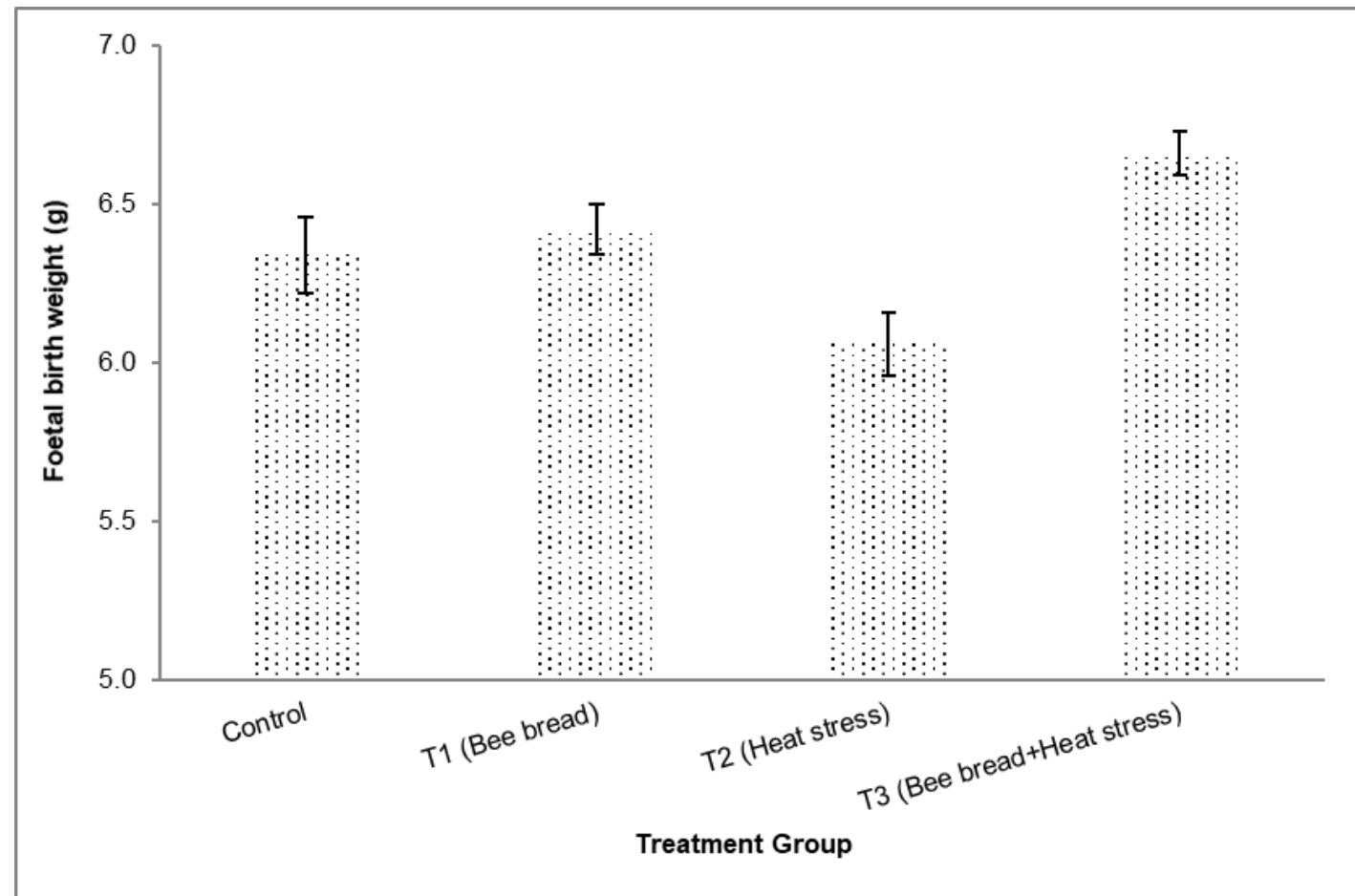

Significant differences were determined by one way ANOVA followed by Tukey's post hoc test with $p<0.05$. Different superscript $(a, b)$ indicates a significant difference.

Figure 6. The foetal birth weight (mean \pm SEM) of female Sprague Dawley rats in different treatment groups which are Control (C: standard feeding treatment), Treatment 1 (T1: Bee bread), Treatment 2 (T2: Heat stress) and Treatment 3 (T3: Bee bread + Heat stress). 
Foetal birth weight was significantly reduced in the T2 group compared with the T1 group (Figure 6). There is no significant difference in foetal birth weight among T1, and T3; but the T3 which was given bee bread treatment had shown the potential of improving the foetal birth weight even under heat stress conditions. Among all experimental groups, no gross congenital abnormalities were observed.

In most studies, heat stress has negatively affected pregnancy outcomes, including spontaneous abortion, low birth weight, growth retardation, and stillbirth [18,19,20,21,22,22,24]. The adverse effect of heat stress on pregnancy outcomes was also observed in the present study. Rats in the T2 group had a significantly higher gestation period than in the control group. Although the gestation length in the T2 group was significantly longer when compared with the control, the length was still considered as an average gestation length in Sprague Dawley rats. However, a previous study also reported a significantly longer gestation period in the stress group compared with the control group [48]. According to the study [48], the longer gestation period observed in stressed rats might be due to an increase of corticosterone levels found in rats from the stress group of the same study. This finding might suggest that a higher corticosterone level could trigger a prolonged gestation period which requires further investigation.

Results from this study show that exposures to heat stress at pregnancy decreased the litter size significantly compared with control, T1 and T3 groups. This result adheres to an earlier study demonstrating a significant reduction of litter size due to daily exposure towards repeated restraint [48]. A study done by Gotz [58] has also resulted in reduced litter sizes when exposed to a chronic psychosocial stressor during pregnancy. It is reported that disturbance in the intrauterine environment for both embryos and uterine tissue caused by exposure to maternal stress after fertilisation resulted a decrease in pregnancy and embryonic death before implantation [13,14]. In addition, Mulder [26] found that foetal growth was restricted due to an increase in corticosterone level that activates the sympathetic nervous system, which caused the flow of blood to the uterus and reduces the number of the foetus which resulting in lower litter size.

Similarly, Brummelte and Galea [59] demonstrated that a high corticosterone level (40 mg/kg) during pregnancy reduces litter size in rats. The lower litter size in the T2 group in the present study might be due to an increase in corticosterone level that requires further investigation. Interestingly, the litter size had significantly increased in the T3 group compared to the T2 group suggesting that bee bread supplementation can improve litter size. A previous study has reported that consuming honey, part of bee bread, improved corticosterone level, resulting in enhanced litter size in maternal stress rats [48] which suggest that bee bread supplementation may improve litter size by decreasing the corticosterone level. Dietary arginine supplementation has been found in a recent research study to increase litter size in pigs [60] and rats [61]. Administration of L-arginine (16 g/day for 8 days) was reported to increase uterine blood flow, endometrial receptivity and pregnancy rate [62] that leading to improved survival and development of mammal's embryos and fetuses [63]. Remarkably, according to a nutritional analysis done by Othman [49], bee bread contain both essential and non-essential amino acid including arginine. Hence, the improved litter size seen in the T3 group could also be partly due to the interaction of these compounds to support foetal growth development which should be addressed in the future study.

A significantly higher percentage of resorption was observed in the T2 group when compared with the control, T1 and T3 groups. The previous research noted that the growth of pre-implantation embryos decreased when exposed to heat stress $\left(39^{\circ} \mathrm{C}-41^{\circ} \mathrm{C}\right)$ at the time of fertilisation [64]. This finding might explain the higher percentage of resorption in the T2 group in this study since the developing embryos were said to be the most sensitive within a limited period in between the fertilisation and implantation as it is the state where they undergo dynamic growth, proliferation and differentiation of cells, and many changes in gene expression [11]. Furthermore, Wolfenson [15] reported that exposure to high temperature could also inhibit the luteal function, which caused a decrease in the levels of progesterone secretion which may have resulted in spontaneous abortion or embryo death [65]. Based on these findings, exposure to heat stress at the early gestation seems to disturb the embryo development, resulting in embryo death, hence, might explain the higher percentage of resorption in the present study. The higher percentage of resorption might explain the reduced litter size found in the T2 group as the number of implantations that was observed on the uterus is higher when compared with the number of delivered pups. This might suggest that some embryo resorption might occur during implantation or early post-implantation stages and reduce the number of pups delivered as seen in the T2 group.

On the contrary, supplementation of bee bread during heat stress significantly reduced the percentage of resorption compared with the heat stress group suggesting that bee bread poses the ability to reduce the effect of heat stress. According to Arechiga [66], an increase in antioxidants such as glutathione during embryonic development could counteract the effect of heat stress. Glutathione is one of the 
antioxidants contained in bee bread [49]. It is very crucial for the foetus and placenta development [67]. It regulates cell differentiation, proliferation and apoptosis, all of which are crucial activities in the developing embryo [68]. Similarly, Sakatani [69] also reported that in vitro antioxidants administration could protect the embryo from the adverse effect of heat shock. Bee bread is also rich in antioxidants like vitamin E, vitamin $\mathrm{P}$ (rutin) and provitamin A (carotene) [70]; these antioxidants may function as a precursor in decreasing the effect of heat stress on the percentage of resorption as demonstrated by T3 in Figure 5. These data, taken together, may point to a probable explanation of bee bread's antioxidant activity, which will require more investigation to understand the actual molecular mechanism of action.

In comparison, heat stress also significantly reduced the foetal birth weight when compared with the T1 and T3 group. The results are similar to previous studies that reported a significant decrease in offspring birth weight delivered from stressed dams [71]. The same findings were also observed in the offspring of stressed mice [72] and snowshoe hares [73]. According to Cheong [74], corticosterone concentrations could also function as a precursor to reducing birth weight in both male and female offspring. Exposure

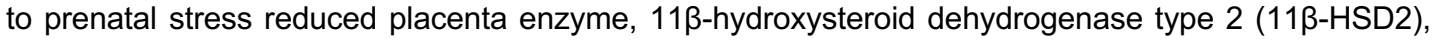
resulting in lower birth weight as deficient in placenta $11 \beta-H S D 2$ permits transfusion of more corticosterone from mother to the foetal [75]. Therefore, a reduction in birth weight reported from the T2 group in this study may be associated with a rise in corticosterone level, as mentioned in previous studies which also required further investigation.

However, the T3 group which was given bee bread treatment had shown the possibility of improving the foetal birth weight even under heat stress conditions. This finding suggests that supplementation of bee bread to rats subjected to heat stress during pregnancy could partly minimize the adverse effect of heat stress. Moreover, bee bread is also rich in both essential and non-essential amino acids [49] According to Hussain [76], essential amino acids play a critical role in foetal development and other vital processes throughout pregnancy, ensuring a healthy pregnancy. It is reported that L-glutamine supplementation in the diet improves nutrition conversion and litter birth weight [76]. Another study conducted by GonzalezAnover [77], shown that supplementation of L-proline was able to enhance reproductive efficiency thus, increasing birth weight.

\section{Conclusions}

The present results revealed that heat stress affects pregnancy outcomes through the reduction litter size and foetal birth weight, and increment of the percentage of resorption and gestation period in Sprague Dawley rats. Whilst, the supplementation of bee bread on pregnant rats exposed to heat stress has shown a positive impact on the pregnancy outcomes; increased litter size, reduced percentage of resorption and increased foetal birth weight. As a natural bee product contains super anti-oxidative potential and nutrients, bee bread may function as a precursor for protection against the adverse effect of heat stress during pregnancy. However, further research especially on the beneficial effect of bee bread, needs to be done for a better understanding of its actual mechanism of action against the effect of heat stress during pregnancy.

\section{Conflicts of interest}

The author(s) declare(s) that there is no conflict of interest regarding the publication of this paper.

\section{Acknowledgements}

The authors would like to acknowledge the Universiti Sultan Zainal Abidin for funding this study (UniSZA/LABMAT/2018/01).

\section{References}

[1] Phillips, C. (2016). The welfare risks and impacts of heat stress on sheep shipped from Australia to the Middle East,Veterinary Journal (London, England: 1997), 218, 78-85.

[2] Anderson, G. B., Bell, M. L. (2011). Heat waves in the United States: mortality risk during heat waves and effect modification by heat wave characteristics in 43 U.S. communities. Environmental Health Perspectives, 119(2), 210-218. 
[3] Haines, A., Kovats, R. S., Campbell-Lendrum, D., Corvalan, C. (2006). Climate change and human health: impacts, vulnerability, and mitigation. Lancet (London, England), 367(9528), 2101-2109.

[4] Loughnan, M., Nicholls, N., Tapper, N. (2010). Mortality-temperature thresholds for ten major population centres in rural Victoria, Australia. Health Place 16(6),1287-1290.

[5] Martiello, M. A., Giacchi, M. V. (2010). High temperatures and health outcomes: a review of the literature. Scandinavian Journal of Public Health, 38(8), 826-837.

[6] Zeng, Q., Li, G., Cui, Y., Jiang, G., Pan, X. (2016). Estimating Temperature-Mortality ExposureResponse Relationships and Optimum Ambient Temperature at the Multi-City Level of China. International Journal of Environmental Research and Public Health, 13(3), 279.

[7] Li, S., Baker, P. J., Jalaludin, B. B., Guo, Y., Marks, G. B., Denison, L. S., Williams, G. M. (2014). Are children's asthmatic symptoms related to ambient temperature? A panel study in Australia. Environmental Research, 133, 239-245.

[8] Dahlquist, M., Raza, A., Bero-Bedada, G., Hollenberg, J., Lind, T., Orsini, N., Sjögren, B., Svensson, L., Ljungman, P. L. (2016). Short-term departures from an optimum ambient temperature are associated with increased risk of out-of-hospital cardiac arrest. International Journal of Hygiene and Environmental Health, 219(4-5), 389-397.

[9] Lanzinger, S., Hampel, R., Breitner, S., Rückerl, R., Kraus, U., Cyrys, J., Geruschkat, U., Peters, A., Schneider, A. (2014). Short-term effects of air temperature on blood pressure and pulse pressure in potentially susceptible individuals. International Journal of Hygiene and Environmental Health, 217(7), 775-784.

[10] Phung, D., Thai, P. K., Guo, Y., Morawska, L., Rutherford, S., Chu, C. (2016). Ambient temperature and risk of cardiovascular hospitalisation: An updated systematic review and metaanalysis. The Science of the Total Environment, 550, 1084-1102.

[11] Takahashi, M. (2011). Heat stress on reproductive function and fertility in mammals. Reproductive Medicine and Biology, 11(1), 37-47.

[12] Roth, Z., Aroyo, A., Yavin, S., Arav, A. (2008). The antioxidant epigallocatechin gallate (EGCG) moderates the deleterious effects of maternal hyperthermia on follicle-enclosed oocytes in mice. Theriogenology, 70(6), 887-897.

[13] Ealy, A. D., Drost, M., Hansen, P. J. (1993). Developmental changes in embryonic resistance to adverse effects of maternal heat stress in cows. Journal of Dairy Science, 76(10), 2899-2905.

[14] Ozawa, M., Hirabayashi, M., Kanai, Y. (2002). Developmental competence and oxidative state of mouse zygotes heat-stressed maternally or in vitro. Reproduction (Cambridge, England), 124(5), 683-689.

[15] Wolfenson, D., Sonego, H., Bloch, A., Shaham-Albalancy, A., Kaim, M., Folman, Y., Meidan, R. (2002). Seasonal differences in progesterone production by luteinised bovine thecal and granulosa cells. Domestic Animal Endocrinology, 22(2), 81-90.

[16] Nakamura, H., Matsuzaki, I., Hatta, K., Ogino, K. (2004). Physiological involvement of placental endothelin-1 and prostaglandin F2alpha in uteroplacental circulatory disturbance in pregnant rats exposed to heat stress. Canadian Journal of Physiology and Pharmacology, 82(4), 225-230.

[17] Schrick, F. N., Inskeep, E. K., Butcher, R. L. (1993). Pregnancy rates for embryos transferred from early postpartum beef cows into recipients with normal estrous cycles. Biology of Reproduction, 49(3), 617-621.

[18] Auger, N., Fraser, W. D., Smargiassi, A., Bilodeau-Bertrand, M., Kosatsky, T. (2017). Elevated outdoor temperatures and risk of stillbirth. International Journal of Epidemiology, 46(1), 200-208.

[19] Arroyo, V., Díaz, J., Carmona, R., Ortiz, C., Linares, C. (2016). Impact of air pollution and temperature on adverse birth outcomes: Madrid, 2001-2009. Environmental Pollution (Barking, Essex: 1987), 218, 1154-1161.

[20] Bruckner, T. A., Modin, B., Vågerö, D. (2014). Cold ambient temperature in utero and birth outcomes in Uppsala, Sweden, 1915-1929. Annals of Epidemiology, 24(2), 116-121.

[21] Dadvand, P., Basagaña, X., Sartini, C., Figueras, F., Vrijheid, M., de Nazelle, A., Sunyer, J., Nieuwenhuijsen, M. J. (2011). Climate extremes and the length of gestation. Environmental Health Perspectives, 119(10), 1449-1453.

[22] Ha, S., Liu, D., Zhu, Y., Kim, S. S., Sherman, S., Mendola, P. (2017a). Ambient Temperature and Early Delivery of Singleton Pregnancies. Environmental Health Perspectives, 125(3), 453-459.

[23] Ha, S., Liu, D., Zhu, Y., Soo Kim, S., Sherman, S., Grantz, K. L., Mendola, P. (2017b). Ambient Temperature and Stillbirth: A Multi-Center Retrospective Cohort Study. Environmental Health Perspectives, 125(6), 067011.

[24] Schifano, P., Asta, F., Dadvand, P., Davoli, M., Basagana, X., Michelozzi, P. (2016). Heat and air pollution exposure as triggers of delivery: A survival analysis of population-based pregnancy cohorts in Rome and Barcelona. Environment International, 88, 153-159.

[25] Lin, Y., Hu, W., Xu, J., Luo, Z., Ye, X., Yan, C., Liu, Z., Tong, S. (2017). Association between temperature and maternal stress during pregnancy. Environmental Research, 158, 421-430.

[26] Mulder, E. J., Robles de Medina, P. G., Huizink, A. C., Van den Bergh, B. R., Buitelaar, J. K., 
Visser, G. H. (2002). Prenatal maternal stress: effects on pregnancy and the (unborn) child. Early Human Development, 70(1-2), 3-14.

[27] Dole, N., Savitz, D. A., Hertz-Picciotto, I., Siega-Riz, A. M., McMahon, M. J., Buekens, P. (2003). Maternal stress and preterm birth. American Journal of Epidemiology, 157(1), 14-24.

[28] Nkansah-Amankra, S., Luchok, K. J., Hussey, J. R., Watkins, K., Liu, X. (2010). Effects of maternal stress on low birth weight and preterm birth outcomes across neighbourhoods of South Carolina, 2000-2003. Maternal and Child Health Journal, 14(2), 215-226.

[29] Puppel, K., Kapusta, A., Kuczyńska, B. (2015). The aetiology of oxidative stress in the various species of animals, a review. Journal of the Science of Food and Agriculture, 95(11), 2179-2184.

[30] Tanaka, Masahito Kamiya, Yuko Kamiya, Mitsuru Nakai, Yutaka. (2007). Effect of high environmental temperatures on ascorbic acid, sulfhydryl residue and oxidised lipid concentrations in plasma of dairy cows. Animal Science Journal. 78. $301-306$.

[31] Boni R. (2019). Heat stress, a serious threat to reproductive function in animals and humans. Molecular Reproduction and Development, 86(10), 1307-1323.

[32] Christen, F., Desrosiers, V., Dupont-Cyr, B. A., Vandenberg, G. W., Le François, N. R., Tardif, J. -C., Blier, P. U. (2018). Thermal tolerance and thermal sensitivity of heart mitochondria: Mitochondrial integrity and ROS production. Free Radical Biology Medicine, 116, 11-18.

[33] Burton, G. J., Jauniaux, E. (2011). Oxidative stress. Best practice research. Clinical Obstetrics Gynaecology, 25(3), 287-299.

[34] Díaz, J., Arroyo, V., Ortiz, C., Carmona, R., Linares, C. (2016). Effect of environmental factors on low weight in non-premature births: a time series analysis. PloS One, 11(10), e0164741.

[35] Barajas, J., Cortes-Rodriguez, M., Rodríguez-Sandoval, E. (2012). Effect of temperature on the drying process of bee pollen from two zones of Colombia. Journal of Food Process Engineering, 35(1), 134-148.

[36] Vásquez, A., Olofsson, T. C. (2009). The lactic acid bacteria involved in the production of bee pollen and bee bread. Journal of Apicultural Research, 48(3), 189-195.

[37] Habryka, C., Kruczek, M., Drygas, B. (2016). Bee products used in apitherapy. World Scientific News, 48, 254-258.

[38] Bakour, M., Al-Waili, N. S., El Menyiy, N., Imtara, H., Figuira, A. C., Al-Waili, T., Lyoussi, B. (2017). Antioxidant activity and protective effect of bee bread (honey and pollen) in aluminum-induced anemia, elevation of inflammatory makers and hepato-renal toxicity. Journal of Food Science and Technology, 54(13), 4205-4212.

[39] Aljadi, Almahdi Mohd Yusoff, Kamaruddin. (2004). Evaluation of the phenolic and antioxidant capacities of two Malaysian floral honeys. Food Chemistry. 85, 513-518.1

[40] Baltrušaitytė V, Venskutonis P R, Čeksterytè V, (2007a). Antibacterial activity of honey and beebread of different origin against $S$. aureus and $S$. epidermidis. Food Technology and Biotechnology 45(2): 201-208.

[41] Baltrušaitytè V, Venskutonis P.R., Čeksterytè V, (2007b). Radical scavenging activity of different floral origin honey and beebread phenolic extracts. Food Chemistry 101(2): 502-514.

[42] Čeksterytė V, (2002). Investigation of pollen composition and catalase activity in unifloral summer and polyfloral spring honey. Žemdirbystè. Mokslodarbai, 80(4): 193- 200.

[43] Kieliszek, M., Piwowarek, K., Kot, A. M., Błażejak, S., Chlebowska-Śmigiel, A., Wolska, I. (2018) Pollen and bee bread as new health-oriented products: A review. Trends in Food Science and Technology. Elsevier Ltd.

[44] Awad, A. L., Beshara, M. M., Ibrahim, A. F., Fahim, H. N. (2013). Effect of using bee bread as a natural supplement on productive and physiological performance of local sinai hens. Egyptian Poultry Science Journal . 5623(33).

[45] Zakaria, F.H, Haron, M. N. (2020). Supplementation of bee bread decreases the abnormal sperm without affecting the sperm count of Sprague-Dawley rats. Bioscience Research, 17, 199-204.

[46] Komosinska-Vassev, K., Olczyk, P., Kaźmierczak, J., Mencner, L., Olczyk, K., (2015). Bee Pollen: Chemical Composition and Therapeutic Application. Evidence-Based Complementary and Alternative Medicine, 15.

[47] OECD. (2008). Part 5: Preparation, Reading and Reporting of Vaginal Smears. OECD Guidelines for the Testing of Chemicals, 116-125.

[48] Haron M.N,. Wan F,. Siti A.S,. Mahaneem M. (2014). Tualang honey ameliorates restraint stressinduced impaired pregnancy outcomes in rats. European Journal of Integrative Medicine, 6(6), 657-663.

[49] Othman, Z.A., Wan Ghazali, W.S, Nordin, L, Omar, N, Mohamed, M. (2019).Nutritional, Phytochemical and Antioxidant Analysis of Bee Bread from Different Regions of Malaysia. Indian Journal Pharmacology Science, 81, 955-960.

[50] Mohd Nor, N. A. N., Haron, M. N. (2018). Effect of Heat Stress on Pregnancy Outcomes in Sprague Dawley Rats. International Journal of Engineering Technology, 7(4.43), 6-9.

[51] Fotsing, D., Ngoupaye, G. T., Ouafo, A. C., Njapdounke, S. K. J., Kenneth, Y. A., Ngo Bum, E. (2017). Effects of Gladiolus dalenii on the stress-induced behavioral, neurochemical, and 
reproductive changes in rat. Frontiers in Pharmacology. 8. 685.

[52] Saraswathi, C. D., Sreemantula, S., and Prakash, W. S. (2010). Effect of chronic cold restraint and immobilisation stress on estrous cycle in rats. Pharmacology. Online 2, 151-160.

[53] Namwanje, M., Brown, C. W. (2016). Activins and inhibins: roles in development, physiology, and disease. Cold Spring Harbor Perspectives in Biology, 8(7), a021881.

[54] Shivalingappa, H., Satyanaranyan, N. D., Purohit, M. G., Sahranabasappa, A., and Patil, S. B. (2002). Effect of ethanol extract of Rivea hypocrateriformis on the estrous cycle of the rat. Journal of Ethnopharmacology. 82, 11-17.

[55] Ozawa, M., Tabayashi, D., Latief, T. A., Shimizu, T., Oshima, I., Kanai, Y. (2005). Alterations in follicular dynamics and steroidogenic abilities induced by heat stress during follicular recruitment in goats. Reproduction, 129(5), 621-630

[56] Paula-Lopes, F. F., Lima, R. S., Satrapa, R. A., Barros, C. M. (2013). Physiology and endocrinology symposium: Influence of cattle genotype (Bos indicus vs. Bos taurus) on oocyte and preimplantation embryo resistance to increased temperature. Journal of Animal Science, 91(3), 1143-1153.

[57] Torres-Júnior, J. R. S., Pires, M. F. A., De sá, W. F., Ferreira, A. M., Viana, J. H. M., Camargo, L. S. A., Baruselli, P. S. (2008). Effect of maternal heat-stress on follicular growth and oocyte competence in Bos indicus cattle. Theriogenology, 69(2), 155-166.

[58] Götz, A. A., Wolf, M., Stefanski, V. (2008). Psychosocial maternal stress during pregnancy: effects on reproduction for F0 and F1 generation laboratory rats. Physiology Behavior, 93(4-5), 1055-1060.

[59] Brummelte, S., Galea, L. A. (2010). Chronic corticosterone during pregnancy and postpartum affects maternal care, cell proliferation and depressive-like behavior in the dam. Hormones and Behavior, 58(5), 769-779.

[60] Mateo, R. D., Wu, G., Bazer, F. W., Park, J. C., Shinzato, I., Kim, S. W. (2007). Dietary L-arginine supplementation enhances the reproductive performance of gilts. The Journal of Nutrition, 137(3), 652-656.

[61] Zeng, X., Wang, F., Fan, X., Yang, W., Zhou, B., Li, P., Yin, Y., Wu, G., Wang, J. (2008). Dietary arginine supplementation during early pregnancy enhances embryonic survival in rats. The Journal of Nutrition, 138(8), 1421-1425.

[62] Battaglia, C., Salvatori, M., Maxia, N., Petraglia, F., Facchinetti, F., Volpe, A. (1999). Adjuvant Larginine treatment for in-vitro fertilization in poor responder patients. Human Reproduction (Oxford, England), 14(7), 1690-1697.

[63] Wu G. (2010). Functional amino acids in growth, reproduction, and health. Advances in Nutrition (Bethesda, Md.), 1(1), 31-37.

[64] Sugiyama S, McGowan M, Phillips N, Kafi M, Young M. (2007). Effects of increased ambient temperature during IVM and/or IVF on the in vitro development of bovine zygotes. Reproductive Domestic Animal. 2007;42:271-4.

[65] Parker, V. J., Douglas, A. J. (2010). Stress in early pregnancy: maternal neuro-endocrine-immune responses and effects. Journal of Reproductive Immunology, 85(1), 86-92.

[66] Aréchiga, C. F., Ealy, A. D., Hansen, P. J. (1995). Evidence that glutathione is involved in thermotolerance of preimplantation murine embryos. Biology of Reproduction, 52(6), 1296-1301.

[67] Sies H. (1991). Oxidative stress: from basic research to clinical application. The American Journal of Medicine, 91(3C), 31S-38S.

[68] Balasubramanian, A., Birundha, S. (2019). Estimation of Glutathione Level in Second Trimester of Pregnancy without Complications.

[69] Sakatani, M., Suda, I., Oki, T., Kobayashi, S., Kobayashi, S., Takahashi, M. (2007). Effects of purple sweet potato anthocyanins on development and intracellular redox status of bovine preimplantation embryos exposed to heat shock. The Journal of Reproduction and Development, 53(3), 605-614.

[70] Hashem, M.N., Simal-Garandara, J., Hassanein, E, M. (2021). Improving productive performance and health of mammals using honeybee products. Antioxidant, 10, 3, 1-25.

[71] Zhang, S., Mesalam, A., Lee, K. L., Song, S. H., Khan, I., Yuan, Y., Wenfa, L. V., Kong, I. K. (2019). Effect of predator stress on the reproductive performance of female mice after nonsurgical embryo transfer. Journal of the American Association for Laboratory Animal Science: JAALAS, 58(3), 304-310.

[72] Zhang, S. Y., Wang, J. Z., Li, J. J., Wei, D. L., Sui, H. S., Zhang, Z. H., Zhou, P., Tan, J. H. (2011). Maternal restraint stress diminishes the developmental potential of oocytes. Biology of Reproduction, 84(4), 672-681.

[73] Sheriff MJ., Krebs CJ., Boonstra R.. (2009). The sensitive hare: sublethal effects of predator stress on reproduction in snowshoe hares. Journal of Animal Ecology 78:1249-1258.

[74] Cheong, J. N., Cuffe, J. S., Jefferies, A. J., Anevska, K., Moritz, K. M., Wlodek, M. E. (2016). SexSpecific Metabolic Outcomes in Offspring of Female Rats Born Small or Exposed to Stress During 
Pregnancy. Endocrinology, 157(11), 4104-4120.

[75] Seckl, J. R. (2001). Glucocorticoid programming of the fetus; adult phenotypes and molecular mechanisms. Molecular and Cellular Endocrinology, 185(1-2), 61-71.

[76] Hussain, T., Tan, B., Murtaza, G., Metwally, E., Yang, H., Kalhoro, M. S., Kalhoro, D. H., Chughtai, M. I., Yin, Y. (2020). Role of Dietary Amino Acids and Nutrient Sensing System in Pregnancy Associated Disorders. Frontiers in pharmacology, 11, 586979.

[77] Gonzalez-Añover, P., and A. Gonzalez-Bulnes. (2017). Maternal age modulates the effects of early-pregnancy L-proline supplementation on the birth-weight of piglets. Animal Reproduction Science 181: 63-68. 